\title{
Heart Fatty Acid-Binding Protein Offers Similar Diagnostic Performance to High-Sensitivity Troponin T in Emergency Room Patients Presenting With Chest Pain
}

Kenji Inoue, MD, PhD; Satoru Suwa, MD; Hiroshi Ohta, MD; Seigo Itoh, MD, PhD; Sonomi Maruyama, MD; Nobuhito Masuda, PhD; Manabu Sugita, MD; Hiroyuki Daida, MD

Background: The aim of the present study was to evaluate the diagnostic accuracy of high-sensitivity troponin $T$ (hsTnT) in patients with suspected acute coronary syndrome (ACS) in comparison to heart fatty acid-binding protein (H-FABP), high-sensitivity C-reactive protein, myeloperoxidase (MPO), and pentraxin 3 (PTX3).

Methods and Results: Patients ( $\mathrm{n}=432$ ) with chest pain were recruited for the analysis. ACS was diagnosed in 298 patients (69\%). The diagnostic accuracy of measurements obtained at presentation, as quantified by the area under the receiver operating curve (AUC), was highest for hsTnT (AUC=0.82; 95\% confidence interval [Cl]: $0.78-$ 0.87 ) and H-FABP (AUC=0.83; 95\%Cl: $0.78-0.87)$. Sensitivity ( $87.9 \%)$ and negative likelihood (LH; 0.2) for hsTnT were the highest and lowest, respectively, but H-FABP had the highest specificity (78.5\%) and positive LH (3.6). Among patients who presented within $2 \mathrm{~h}$ after the onset of chest pain, MPO had the highest AUC $(0.82 ; 95 \% \mathrm{Cl}$ : 0.69-0.94). Combined use of H-FABP and MPO measurements yielded a sensitivity of $69.2 \%$, specificity of $84.2 \%$, positive $\mathrm{LH}$ of 4.4 , and negative $\mathrm{LH}$ of 0.4 .

Conclusions: The hsTnT assay offers excellent diagnostic performance to rule out ACS, but it is prone to falsepositive results. H-FABP offers similar overall diagnostic performance, while the combination of H-FABP and MPO assays may improve the diagnosis of ACS, particularly in patients with recent onset of chest pain. (Circ $J$ 2011; 75: 2813-2820)

Key Words: Acute coronary syndrome; Biomarker; Diagnostic performance

$\mathbf{C}$ ardiac biomarkers are important both in risk stratification and in choice of treatment strategies for patients with acute coronary syndrome (ACS). Over the past several years, advances in methodologies for protein identification and a greater understanding of the inflammatory pathophysiology of atherothrombosis have contributed to development of candidate biomarkers in ACS, including the following. Heart-type fatty acid-binding protein (H-FABP), a cytosolic protein mainly expressed by cardiomyocytes, is an early cardiac marker because it appears in plasma $1-3 \mathrm{~h}$ after cardiac damage. ${ }^{1-3}$ Myeloperoxidase (MPO), a lysosomal protein stored in azurophilic granules of the neutrophils, has been found to predict cardiovascular disease development (oxidative stress or plaque vulnerability). ${ }^{4-6}$ High-sensitivity C-reactive protein (hsCRP), an inflammation protein, is well known as a cardiovascular marker. ${ }^{7,8}$ Pentraxin 3 (PTX3), a new vascular inflammation marker, is increased in patients with ACS or congestive heart failure. ${ }^{9-11}$ To date, however, cardiac troponin $\mathrm{T}$ remains the most established biomarker for diagnosis of ACS, and recent guidelines recommend that troponins are the only necrosis markers that should be measured routinely for patients with suspected ACS. ${ }^{12}$

\section{Editorial p 2753}

Although evidence supporting routine measurement of troponins abound, these tests have some limitations. First, the release of troponin is slow, and it takes several hours to reach

Received June 8, 2011; revised manuscript received July 29, 2011; accepted August 18, 2011; released online September 21 , 2011 Time for primary review: 20 days

Department of Cardiology (K.I., S.M.), Department of Emergency and Critical Care Medicine (M.S.), Juntendo University Nerima Hospital, Tokyo; Department of Cardiology, Juntendo University School of Medicine, Tokyo (S.I., H.D.); Department of Cardiology, Itabashi Chuo General Hospital, Tokyo (H.O.); Perseus Proteomics Incorporated, Tokyo (N.M.); and Department of Cardiology, Juntendo University Shizuoka Hospital, Shizuoka (S.S.), Japan

Mailing address: Kenji Inoue, MD, PhD, Department of Cardiology, Juntendo University Nerima Hospital, 3-1-10 Takanodai, Nerima-ku, Tokyo 177-8521, Japan. E-mail: inouelsbm@yahoo.co.jp

ISSN-1346-9843 doi:10.1253/circj.CJ-11-0598

All rights are reserved to the Japanese Circulation Society. For permissions, please e-mail: cj@j-circ.or.jp 


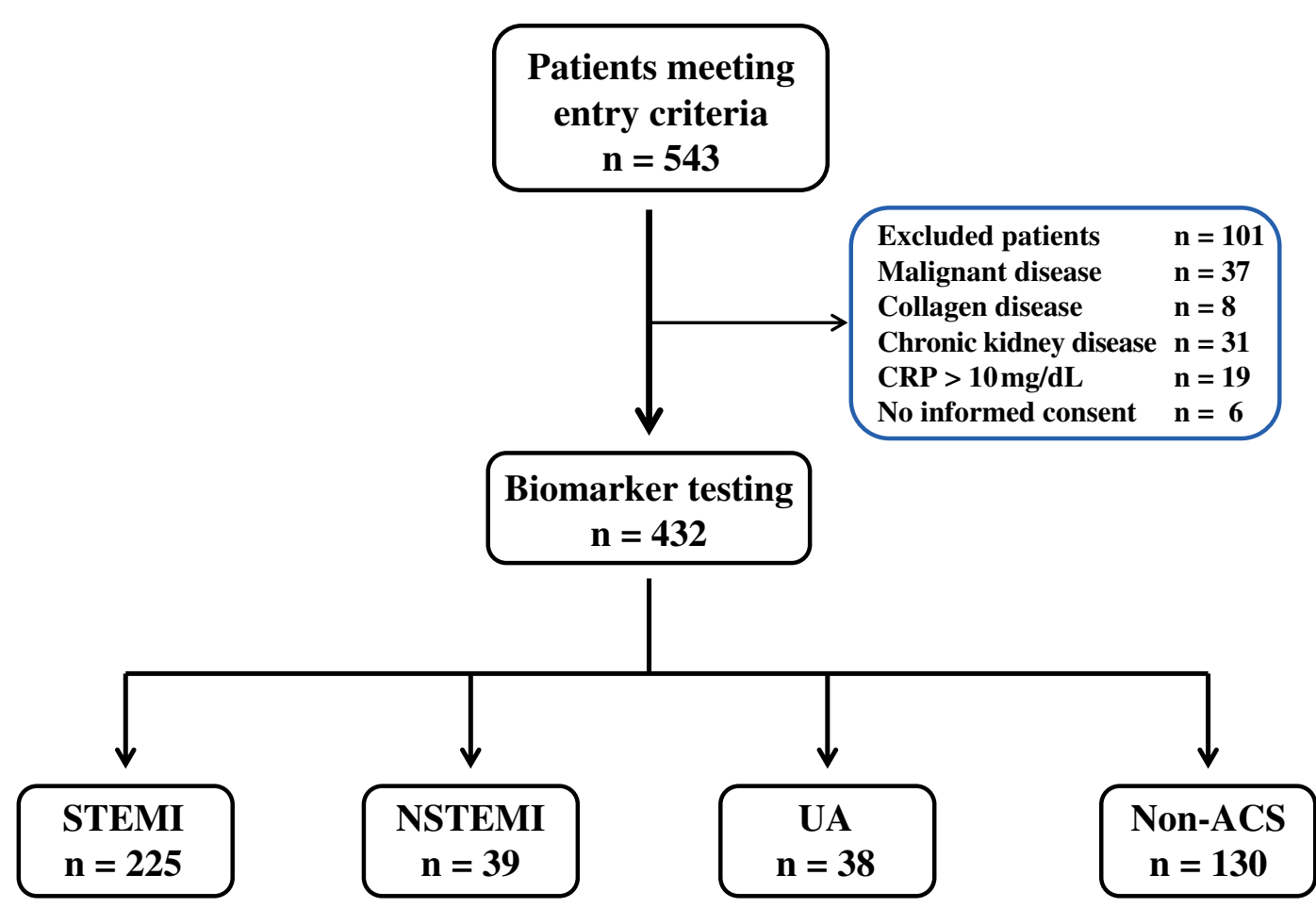

Figure 1. Flowchart of patient enrollment into the study. CRP, C-reactive protein; Non-ACS, non-acute coronary syndrome; NSTEMI, non-ST elevation myocardial infarction; STEMI, ST elevation myocardial infarction; UA, unstable angina pectoris.

measurable levels in blood: generally, levels that can be measured with adequate sensitivity and specificity are achieved only around $6 \mathrm{~h}$ after the onset of cardiac necrosis. Recently, however, a high-sensitivity troponin $\mathrm{T}$ (hsTnT) assay has been developed, permitting measurement of concentrations that are 10 -fold lower than those measurable with conventional assays. ${ }^{13,14}$ A second problem remains, however; namely, troponin levels are also reported to be elevated in patients with other medical conditions, such as congestive heart failure, myocarditis, or renal failure, making the test less suitable for diagnosis of ACS. ${ }^{15-17}$

In the present study we compared the efficacy of using troponin levels, measured with the hsTnT assay, to other cardiac biomarkers, in patients with chest pain.

\section{Methods}

\section{Patient Selection}

This was a multicenter, cross-observational study, in which 543 patients with chest pain (lasting $>20$ min within $24 \mathrm{~h}$ of admission) were enrolled. These patients had all visited the emergency department of hospitals by ambulance during the 3-year recruitment period from March 2006 to April 2009. Of these, the following patients were excluded: those (1) who were unwilling or unable to provide informed consent; (2) who were admitted with an identified chronic kidney disease, as indicated by serum creatinine level $>1.5 \mathrm{mg} / \mathrm{dl}$ on presentation; or (3) who were diagnosed with and treated for malignant disease or collagen disease; or (4) whose CRP levels were $>10 \mathrm{mg} / \mathrm{dl}$, with an identified non-cardiac cause of chest pain on presentation. ${ }^{18,19}$ Finally, a total of 432 subjects were analyzed (Figure 1).
Informed consent was obtained from all subjects. The study was approved by the ethics committees of Juntendo University Shizuoka Hospital and Juntendo University Nerima Hospital as well as Itabashi Chuo Hospital, and was conducted in accordance with the Helsinki Declaration of 1971, as revised in 1983.

\section{Clinical Assessment}

All patients underwent an initial clinical assessment that included a clinical history, physical examination, 12-lead electrocardiogram (ECG), continuous ECG monitoring, pulse oximetry, standard blood pressure measurements, and chest radiography in the emergency department.

Weight, height, body mass index, ECG, and systolic and diastolic blood pressures (measured in the supine position) were assessed under standardized conditions. Information with respect to smoking status (current or former smoker vs. non-smoker) was obtained via a questionnaire.

\section{Final Diagnosis}

Diagnostic outcome was categorized into 4 groups: (1) STelevation myocardial infarction (STEMI); (2) non-STEMI (NSTEMI); (3) unstable angina (UA); and (4) no ACS (which included cases of atypical chest pain). Diagnoses were adjudicated by 2 senior cardiologists according to the Joint Guidelines of the European Society of Cardiology and American College of Cardiology Committee. ${ }^{20}$ The diagnosis of atypical chest pain was based on absence of significant findings indicative of cardiovascular problems, including laboratory tests, ECG, and chest radiography. Such a diagnosis was subsequently confirmed when follow-up by chart review by a senior cardiologist indicated that the patient did not return to a hospital 


\begin{tabular}{|c|c|c|c|c|}
\hline Characteristic & $\begin{array}{l}\text { All Patients } \\
(\mathrm{n}=432)\end{array}$ & $\begin{array}{l}\text { Patients with ACS } \\
(n=298)\end{array}$ & $\begin{array}{l}\text { Patients without ACS } \\
\qquad(n=134)\end{array}$ & $P$ value \\
\hline \multicolumn{5}{|l|}{ Age (years) } \\
\hline Median & 67 & 67 & 65 & 0.8 \\
\hline IQR & 59-75 & 59-75 & $58-75$ & \\
\hline Male sex, n (\%) & $314(73)$ & $229(77)$ & $85(64)$ & \\
\hline \multicolumn{5}{|l|}{ Risk factors, n (\%) } \\
\hline Hypertension & $224(51.9)$ & $166(55.7)$ & $70(56.1)$ & 0.96 \\
\hline Dyslipidemia & $191(44.2)$ & $137(46.0)$ & $59(40.6)$ & 0.27 \\
\hline Diabetes & $127(29.4)$ & 98 (32.9) & $39(22.6)$ & 0.02 \\
\hline Current smoking & $153(35.5)$ & $116(38.9)$ & $48(29.0)$ & 0.04 \\
\hline History of smoking & 66 (15.2) & $44(14.8)$ & $20(16.1)$ & 0.71 \\
\hline \multicolumn{5}{|l|}{ Clinical findings } \\
\hline \multicolumn{5}{|l|}{ Heart rate (beats/min) } \\
\hline Median & 78 & 79 & 73 & 0.9 \\
\hline IQR & $66-89$ & $66-90$ & $64-83$ & \\
\hline \multicolumn{5}{|c|}{ Blood pressure $(\mathrm{mmHg})$} \\
\hline \multicolumn{5}{|l|}{ Systolic } \\
\hline Median & 135 & 133 & 132 & 0.07 \\
\hline IQR & $118-150$ & $112-151$ & $122-146$ & \\
\hline \multicolumn{5}{|l|}{ Diastolic } \\
\hline Median & 78 & 79 & 72 & 0.6 \\
\hline IQR & $66-90$ & $66-103$ & $66-82$ & \\
\hline \multicolumn{5}{|l|}{ Body mass index } \\
\hline Median & 23.8 & 24.0 & 23.3 & 0.6 \\
\hline IQR & $21.1-26.3$ & $21.5-26.0$ & $21.0-26.4$ & \\
\hline \multicolumn{5}{|l|}{ Creatinine (mg/dl) } \\
\hline Median & 0.8 & 0.9 & 0.7 & 0.09 \\
\hline IQR & $0.63-0.97$ & $0.7-1.0$ & $0.6-0.9$ & \\
\hline \multicolumn{5}{|c|}{ eGFR $\left(\mathrm{ml} \cdot \mathrm{min}^{-1} \cdot 1.73 \mathrm{~m}^{-2}\right)$} \\
\hline Median & 67.1 & 72.3 & 64.3 & 0.09 \\
\hline IQR & $59.8-78.2$ & $63.9-92.6$ & $57.0-75.0$ & \\
\hline
\end{tabular}

ACS, acute coronary syndrome; IQR, interquartile range.

within 1 month of the visit to the emergency department.

\section{Laboratory Analysis}

Venous blood samples were drawn in the emergency department on admission and were stored at $-70^{\circ} \mathrm{C}$, for $<3$ years, until analysis. All measurements were performed in duplicate and blinded to patient data.

Serum troponin was measured on hsTnT assay using an Elecsys 2010 system (Roche Diagnostics, Basel, Switzerland). Serum H-FABP measurement was performed using the MARKIT-M H-FABP assay (DS Pharma Biomedical, Osaka, Japan). Serum hsCRP assay was carried out with latex-enhanced immunonephelometry reagents (SRL, Tachikawa, Tokyo, Japan) on a BN ProSpec analyzer (Siemens Healthcare Diagnostics, Deerfield, IL, USA). Plasma MPO or PTX3 was determined on sandwich immunoassay (Mercodia, Uppsala, Kingdom of Sweden, or Perseus Proteomic, Tokyo, Japan).

Cut-offs for hsTnT, H-FABP, and hsCRP were defined according to the manufacturers of the respective assay kits as follows: hsTnT, $0.014 \mathrm{ng} / \mathrm{ml}$; H-FABP, $6.2 \mathrm{ng} / \mathrm{ml}$; and hsCRP, $1.5 \mathrm{ng} / \mathrm{ml} .{ }^{21}$ Cut-off concentrations for PTX3 $(3.48 \mathrm{ng} / \mathrm{ml})$ and MPO $(87.6 \mu \mathrm{g} / \mathrm{ml})$ were determined according to the highest sensitivity and specificity criterion derived directly from the receiver operating characteristic (ROC) curves.

\section{Statistical Analysis}

Continuous variables are presented as medians (with interquartile range), and categorical variables are presented as numbers and percentages. Continuous variables were compared using Mann-Whitney U-test and categorical variables with the Pearson chi-squared test. Parametric tests such as Pearson's product-moment correlation coefficient analysis were used after $\log$ transformation of original data, because biomarker values were not normally distributed, but approximated a log-normal distribution. Pearson's product-moment correlation coefficient (R) was used to study the relationship between the biomarkers.

The ROC curves were constructed to assess the sensitivity and specificity of cardiac biomarker measurements obtained at specific time points and to compare their ability to diagnose ACS. The comparison of areas under the ROC curves (AUC) was performed. The AUC are expressed with confidence intervals (CI).

All hypothesis testing was 2-tailed, and $\mathrm{P}<0.05$ was considered statistically significant. Statistical analysis was performed using SPSS version 16.0 (SPSS, Chicago, IL, USA).

\section{Results}

Patient Characteristics

Baseline characteristics of the 432 subjects are given in 


\begin{tabular}{|c|c|c|c|c|}
\hline & Log H-FABP & Log hsCRP & Log MPO & Log РTX3 \\
\hline \multicolumn{5}{|l|}{ Log hsTnT } \\
\hline $\mathrm{R}$ & 0.69 & 0.40 & 0.47 & 0.60 \\
\hline$P$ value & $<0.001$ & $<0.001$ & $<0.001$ & $<0.001$ \\
\hline \multicolumn{5}{|c|}{ Log H-FABP } \\
\hline $\mathrm{R}$ & & 0.11 & 0.45 & 0.52 \\
\hline$P$ value & & 0.02 & $<0.001$ & $<0.001$ \\
\hline \multicolumn{5}{|c|}{ Log hsCRP } \\
\hline $\mathrm{R}$ & & & 0.23 & 0.39 \\
\hline$P$ value & & & $<0.001$ & $<0.001$ \\
\hline \multicolumn{5}{|l|}{ Log MPO } \\
\hline $\mathrm{R}$ & & & & 0.49 \\
\hline$P$ value & & & & $<0.001$ \\
\hline
\end{tabular}

$\mathrm{H}-\mathrm{FABP}$, heart fatty acid-binding protein; hsCRP, high-sensitivity C-reactive protein; hsTnT, high-sensitivity troponin T; MPO, myeloperoxidase; PTX3, pentraxin 3.

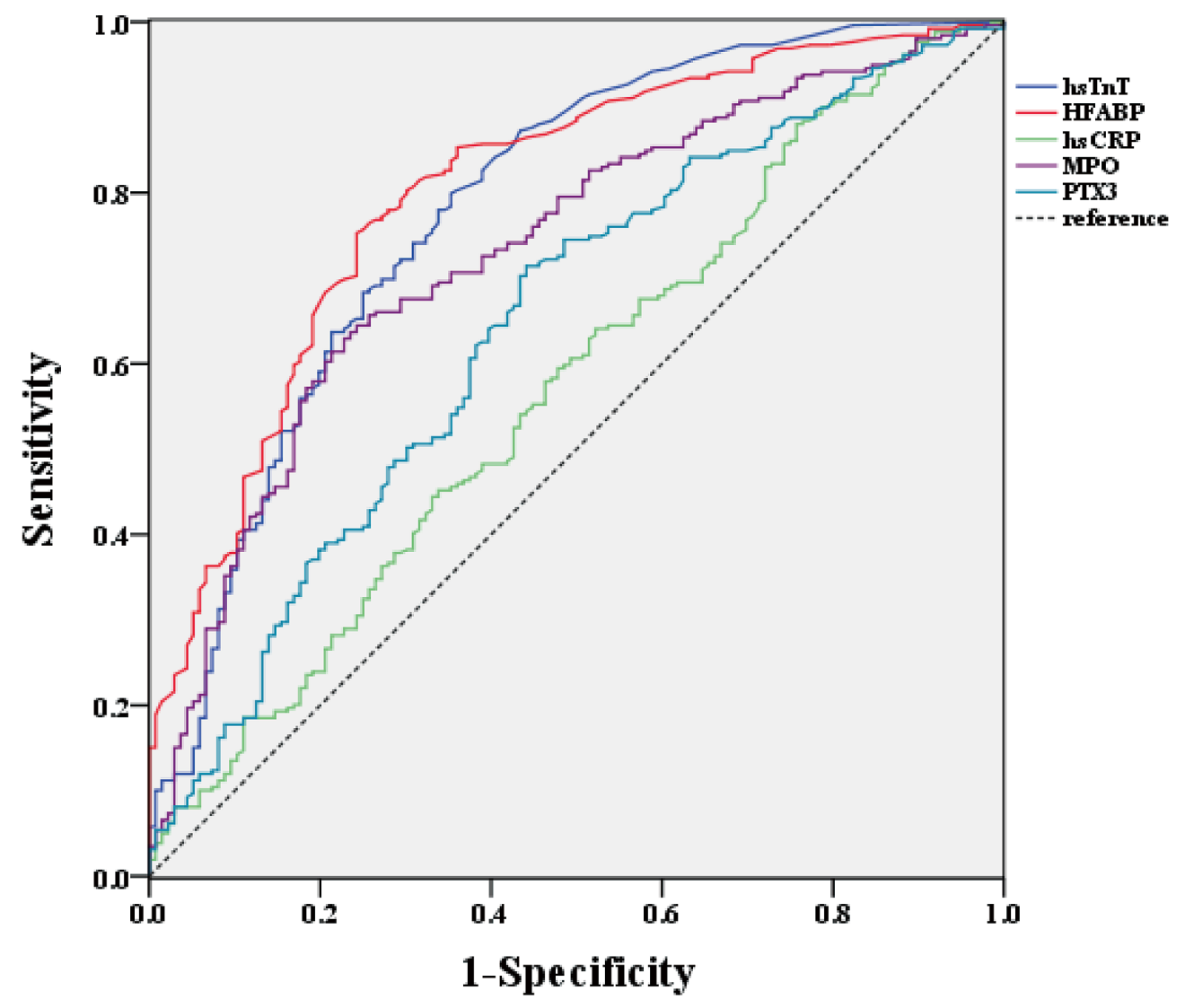

Figure 2. Receiver operating characteristic curves showing diagnostic performance of the 5 cardiac biomarker assays on blood samples of the overall cohort, obtained at presentation for the diagnosis of acute coronary syndrome. H-FABP, heart fatty acid-binding protein; hsCRP, high-sensitivity C-reactive protein; hsTnT, high-sensitivity troponin T; MPO, myeloperoxidase; PTX3, pentraxin 3.

Table 1. There were no significant differences in patients with ACS or without ACS, besides the presence of diabetes mellitus or current smoking. ACS was the final diagnosis in $69.0 \%$ of the patients (STEMI in 52\%, NSTEMI in $9.0 \%$, and UA in $8.8 \%$; Figure 1). The non-ACS group included patients with vasospastic angina pectoris (VAP, $4.9 \%$ of the total cohort), patients with cardiac symptoms from causes other than coro- nary artery disease $(7.1 \%$; of which patients with Takotsubo myocarditis accounted for $3.4 \%$ ), and patients with symptoms of unknown origin $(19.0 \%)$.

\section{Cardiac Biomarkers}

The relation between cardiac biomarkers was investigated using Pearson's correlation coefficient (Table 2). A highly sta- 


\begin{tabular}{|lcccccccc|}
\multicolumn{2}{l}{ Table 3. Diagnostic Performance of Cardiac Markers } \\
\multicolumn{1}{c}{ Assay } & AUC & $\mathbf{9 5 \%}$ Cl & $\begin{array}{c}\text { Sensitivity } \\
\text { (\%) }\end{array}$ & $\begin{array}{c}\text { Specificity } \\
\text { (\%) }\end{array}$ & $\begin{array}{c}\text { Positive } \\
\text { likelihood }\end{array}$ & $\begin{array}{c}\text { Negative } \\
\text { likelihood }\end{array}$ & $\begin{array}{c}\text { PPV } \\
\text { (\%) }\end{array}$ & $\begin{array}{c}\text { NPV } \\
\text { (\%) }\end{array}$ \\
hsTnT & 0.82 & $0.78-0.87$ & 87.9 & 61.2 & 2.3 & 0.2 & 83.4 & 69.5 \\
H-FABP & 0.83 & $0.78-0.87$ & 78.5 & 78.2 & 3.6 & 0.3 & 89.0 & 61.9 \\
hsCRP & 0.62 & $0.56-0.68$ & 45.3 & 70.1 & 1.5 & 0.8 & 77.1 & 36.6 \\
MPO & 0.75 & $0.70-0.81$ & 67.3 & 72.6 & 2.5 & 0.5 & 84.7 & 49.7 \\
PTX3 & 0.72 & $0.66-0.77$ & 60.7 & 71.6 & 2.1 & 0.5 & 82.6 & 45.1 \\
\hline
\end{tabular}

AUC, area under the curve; $\mathrm{Cl}$, confidence interval; $\mathrm{H}-\mathrm{FABP}$, heart fatty acid-binding protein; hsCRP, high-sensitivity C-reactive protein; hsTnT, high-sensitivity troponin T; MPO, myeloperoxidase; NPV, negative predictive value; PPV, positive predictive value; PTX3, pentraxin 3.

\begin{tabular}{|c|c|c|c|c|c|c|c|c|}
\hline Assay & AUC & $95 \% \mathrm{Cl}$ & $\begin{array}{c}\text { Sensitivity } \\
(\%)\end{array}$ & $\begin{array}{c}\text { Specificity } \\
(\%)\end{array}$ & $\begin{array}{l}\text { Positive } \\
\text { likelihood }\end{array}$ & $\begin{array}{l}\text { Negative } \\
\text { likelihood }\end{array}$ & $\begin{array}{l}\text { PPV } \\
(\%)\end{array}$ & $\begin{array}{l}\text { NPV } \\
\text { (\%) }\end{array}$ \\
\hline \multicolumn{9}{|l|}{ STEMI } \\
\hline hsTnT & 0.73 & $0.69-0.78$ & 89.7 & 61.2 & 2.3 & 0.2 & 79.4 & 78.1 \\
\hline H-FABP & 0.80 & $0.76-0.85$ & 85.2 & 78.2 & 3.9 & 0.2 & 86.8 & 75.9 \\
\hline hsCRP & 0.58 & $0.52-0.63$ & 48.0 & 70.1 & 1.6 & 0.7 & 72.8 & 44.8 \\
\hline MPO & 0.65 & $0.60-0.70$ & 70.6 & 72.6 & 2.6 & 0.4 & 81.6 & 59.0 \\
\hline РTX3 & 0.71 & $0.66-0.76$ & 62.8 & 71.6 & 2.2 & 0.5 & 78.7 & 53.6 \\
\hline \multicolumn{9}{|l|}{ NSTEMI } \\
\hline hsTnT & 0.71 & $0.65-0.77$ & 82.7 & 61.2 & 2.1 & 0.3 & 54.4 & 86.3 \\
\hline $\mathrm{H}-\mathrm{FABP}$ & 0.52 & $0.43-0.61$ & 58.7 & 78.2 & 2.7 & 0.5 & 60.3 & 77.0 \\
\hline hsCRP & 0.53 & $0.43-0.64$ & 37.3 & 70.1 & 1.3 & 0.9 & 41.2 & 66.7 \\
\hline MPO & 0.56 & $0.46-0.66$ & 57.4 & 72.6 & 2.1 & 0.6 & 52.2 & 76.6 \\
\hline PTX3 & 0.52 & $0.41-0.62$ & 54.7 & 71.6 & 1.9 & 0.6 & 51.9 & 73.8 \\
\hline
\end{tabular}

STEMI, ST-elevation myocardial infarction; NSTEMI, non-STEMI. Other abbreviations see in Table 3.

tistically significant positive correlation was observed in patients with chest pain between $\log$ hsTnT and both log H-FABP and $\log$ PTX3. Pearson's correlation coefficient (R) and the corresponding $\mathrm{P}$-values for these correlations were $\mathrm{R}=0.69$ and 0.60 , respectively, and $\mathrm{P}<0.001$.

\section{Diagnostic Accuracy of Cardiac Biomarkers at Presentation}

The diagnostic accuracy for ACS, as quantified using AUC, is shown in Figure 2. The AUC of cardiac biomarkers were as follows: hsTnT, AUC $=0.82$, 95\%CI: $0.78-0.87$; H-FABP, AUC $=0.83$, 95\%CI: 0.78-0.87; hsCRP, AUC $=0.62,95 \% \mathrm{CI}$ : 0.56-0.68; MPO, AUC $=0.75$, 95\%CI: 0.70-0.81; and PTX3, AUC $=0.72$, 95\%CI: 0.66-0.77. Among these biomarkers, sensitivity $(87.9 \%)$, negative likelihood ( $\mathrm{LH} ; 0.2)$, and negative predictive value $(69.5 \%)$ was the highest for hsTnT. H-FABP, however, had the highest specificity (78.5\%), positive LH (3.6), and positive predictive value (89.0\%; Table 3). Although both sensitivity and specificity of the new vascular inflammation biomarker, PTX3, was superior to those of the classical inflammation biomarker, hsCRP, its specificity was still low.

The pathophysiology underlying development of STEMI vs. NSTEMI would be expected to be different, and the release-kinetics of biomarkers would therefore also be different. Therefore, we further analyzed patients with STEMI and NSTEMI, separately (Tables 4), but we found that diagnostic performance tended to be similar. The sensitivity $(89.7 \%$ and $82.7 \%$ in STEMI and NSTEMI, respectively), negative LH $(0.2,0.3)$, and negative predictive value $(78.1 \%, 86.3 \%)$ were the highest for hsTnT, but H-FABP had the highest specificity $(78.2 \%, 78.2 \%)$, positive $\mathrm{LH}(3.9,2.7)$, and positive predictive value $(86.8 \%, 60.3 \%)$ in patients with STEMI, as well as in those with NSTEMI.

Overall, the values obtained for specificity were not particularly high in the present study. Therefore, we investigated the characteristics of the non-ACS groups who had levels higher than the cut-off for each biomarker (ie, false-positive results). All biomarkers, except for H-FABP, tested positive in approximately $20 \%$ of subjects with atypical chest pain; H-FABP tested positive in only approximately half of these patients $(11 \%)$. Takotsubo cardiomyopathy patients frequently tested positive for all biomarkers, while VAP caused increased levels of hsTnT in $62 \%$ of patients, presumably because of minor myocardial injury caused by this condition (Table S1).

\section{Cardiac Biomarkers at Presentation in Patients With Recent Onset of Chest Pain}

Next, we investigated serial diagnostic measurements taken for each cardiac biomarker after the onset of chest pain. Although the sensitivity of hsTnT was the highest in patients who presented $3 \mathrm{~h}$ after the onset of chest pain, this marker performed worst in terms of specificity throughout the time course (Figure 3a). Positive LH and predictive value of H-FABP were superior to all biomarkers in patients who presented $>3 \mathrm{~h}$ after the onset of chest pain (Figures $\mathbf{3 b}, \mathbf{c}$ ). In contrast, the specificity of hsCRP was the highest in patients who presented within $6 \mathrm{~h}$ after chest pain, and a positive $\mathrm{LH}$ for this marker was the highest in patients who presented within $2 \mathrm{~h}$. Although the sensitivity was worst (Figure 3d; Table 5), the negative LH was $>0.6$ through the time course and the AUC was not low except $<2 \mathrm{~h}$ after onset of chest pain.

The AUC of hsTnT, H-FABP, and PTX3 gradually increased in a time-dependent manner. Four hours after the onset 


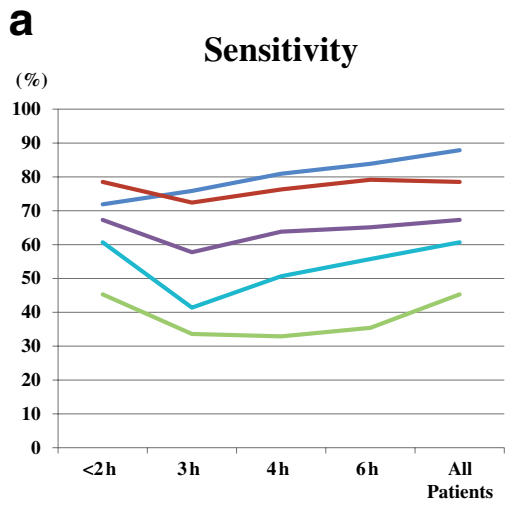

Hours since onset of symptoms

\section{b}

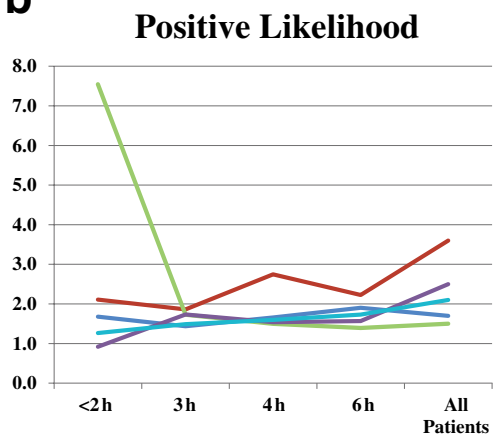

Hours since onset of symptoms

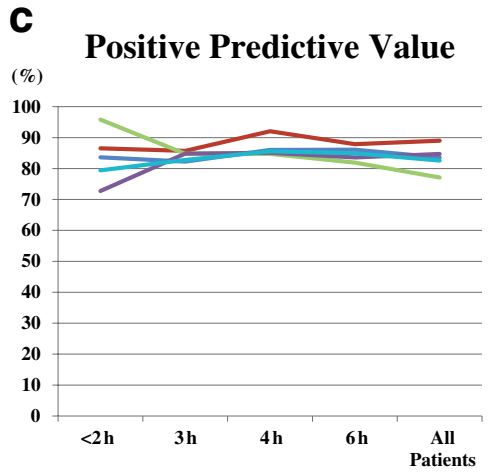

Hours since onset of symptoms

d

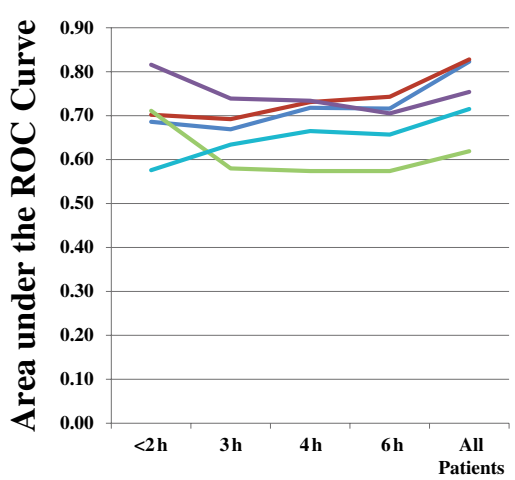

Hours since onset of symptoms

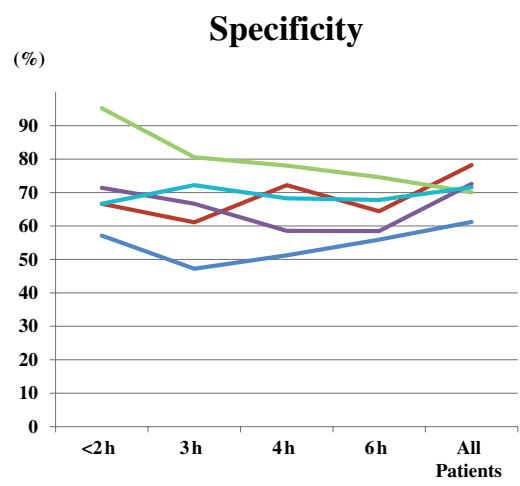

Hours since onset of symptoms

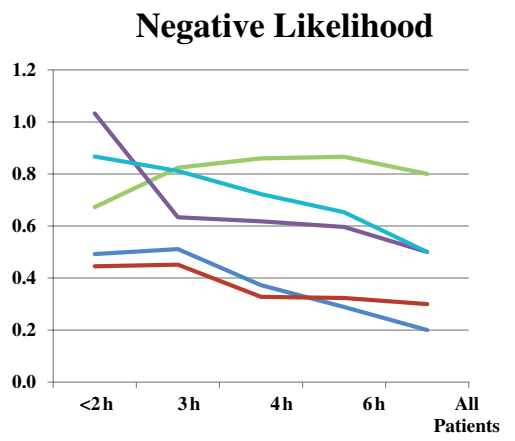

Hours since onset of symptoms

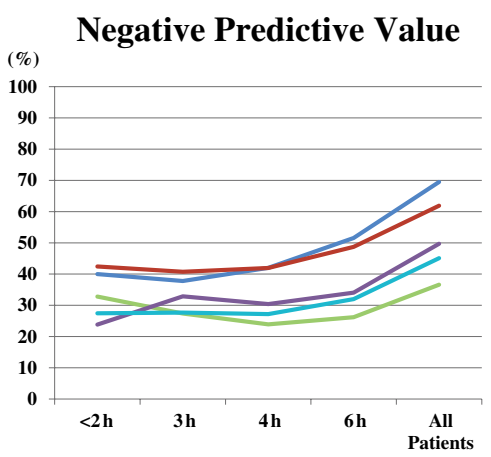

Hours since onset of symptoms

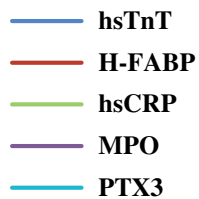

Figure 3. Diagnostic performance, including (a) sensitivity and specificity, (b) likelihood, (c) predictive value, and (d) area under the receiver operating characteristic (ROC) curve, according to the time since the onset of chest pain, for the 5 cardiac biomarkers. Tests were performed on blood samples obtained from patients at presentation for the diagnosis of acute coronary syndrome. H-FABP, heart fatty acid-binding protein; hsCRP, high-sensitivity C-reactive protein; hsTnT, high-sensitivity troponin T; MPO, myeloperoxidase; PTX3, pentraxin 3. 


\begin{tabular}{|lccccc|}
\hline \multicolumn{7}{|c}{ Table 5. Serial AUC of Cardiac Markers } & & & & \\
& $\mathbf{2 h}$ & $\mathbf{3 h}$ & $\mathbf{4 h}$ & $\mathbf{6 h}$ & All ptients \\
$\mathrm{n}$ & 85 & 152 & 193 & 252 & 432 \\
$\mathrm{hsTnT}$ & 0.67 & 0.67 & 0.72 & 0.72 & 0.82 \\
$95 \% \mathrm{Cl}$ & $0.54-0.86$ & $0.56-0.78$ & $0.62-0.82$ & $0.63-0.80$ & $0.78-0.87$ \\
$\mathrm{H}-\mathrm{FABP}$ & 0.7 & 0.69 & 0.73 & 0.74 & 0.83 \\
$95 \% \mathrm{Cl}$ & $0.56-0.85$ & $0.58-0.81$ & $0.63-0.83$ & $0.67-0.82$ & $0.78-0.87$ \\
$\mathrm{hSCRP}$ & 0.71 & 0.58 & 0.57 & 0.57 & 0.62 \\
$95 \% \mathrm{Cl}$ & $0.59-0.83$ & $0.47-0.69$ & $0.47-0.68$ & $0.49-0.66$ & $0.56-0.68$ \\
$\mathrm{MPO}$ & 0.82 & 0.74 & 0.73 & 0.71 & 0.75 \\
$95 \% \mathrm{Cl}$ & $0.69-0.94$ & $0.64-0.84$ & $0.64-0.83$ & $0.62-0.79$ & $0.70-0.81$ \\
$\mathrm{PTX} 3$ & 0.58 & 0.63 & 0.67 & 0.66 & 0.72 \\
$95 \% \mathrm{Cl}$ & $0.44-0.71$ & $0.53-0.74$ & $0.57-0.76$ & $0.57-0.74$ & $0.66-0.77$ \\
\hline
\end{tabular}

Abbreviations see in Table 3.

of chest pain, the AUC of hsTnT and H-FABP was $>0.70$, but throughout all time points, H-FABP was superior to hsTnT. Interestingly, among patients who presented within $2 \mathrm{~h}$ after the onset of chest pain $(n=85)$, the AUC for MPO was the highest among the cardiac biomarkers tested $(\mathrm{AUC}=0.82$; 95\%CI: 0.69-0.94), and the AUC was $>0.70$ at all points. When using a combined measurement of H-FABP and MPO, sensitivity was $69.2 \%$, and the specificity was $84.2 \%$, while positive LH was 4.4, and negative LH was 0.4. Thus, the combination of H-FABP and MPO assay results may improve the diagnostic performance of biomarker testing for patients who present within $2 \mathrm{~h}$ after the onset of chest pain.

\section{Discussion}

This multicenter study examined the diagnostic performance of a new, sensitive cardiac troponin assay, in comparison with tests for other biomarkers, for the early diagnosis of ACS at the time of presentation to the emergency department. Although hsTnT is much improved over the conventional troponin $\mathrm{T}$ assay system, the present results show that many more falsepositive hsTnT tests than false-positive H-FABP tests occurred in patients with non-ACS.

The present study contained patients with VAP (4.7\%) and Takotsubo myocarditis (3.6\%). Thus, cardiac myocardial injury caused by these diseases can generate false-positive findings in assays, when considering positive tests in the presence of chest pain as indicative of ACS (Table S1). This may lead to a reduction in diagnostic performance, especially in the specificity of the hsTnT assay. Patients with Takotsubo cardiomyopathy and VAP typically complain of chest pain and have inverted T or ST elevation; coronary angiography is therefore required to confirm diagnosis, or at least to rule out ACS in these cases. Thus, physicians must consider that these cases may be included when finding elevated cardiac biomarkers in patients with chest pain.

As expected, however, the availability of the hsTnT assay has much improved the sensitivity of troponin T testing; its sensitivity was superior to all biomarkers throughout the time course in the present study. The hsTnT assay may be particularly useful to rule out ACS because the negative LH of a positive hsTnT test was 0.2 in the present study. In contrast, a positive LH of H-FABP was 3.6, the highest among the cardiac biomarkers evaluated in the present study, potentially making it a more accurate test for ACS. The AUC of both hsTnT and $\mathrm{H}-\mathrm{FABP}$ assays were $>0.80$ in all subjects.

Despite this, it is still difficult to determine diagnosis in pa- tients with ACS who present at emergency centers with chest pain within $2 \mathrm{~h}$ after onset of the pain. Interestingly the AUC of MPO was the highest (0.82; 95\%CI: 0.69-0.94) among all biomarkers tested in this cohort. The principal sources of MPO are activated neutrophils and monocytes. MPO has been identified in human plaques, ${ }^{22}$ after activation, MPO was released quickly from neutrophils, and levels became elevated in patients with ACS. In contrast, H-FABP is known to increase faster in patients with early onset ACS. ${ }^{23}$ Thus, the combination of H-FABP and MPO assays may improve the diagnostic performance of cardiac biomarker testing. Moreover, it seems to be sensible to consider that ACS is present in those patients who presented within $2 \mathrm{~h}$ after the onset of chest pain if both H-FABP and MPO tested positive.

A limitation of the present study was the low prevalence of NSTEMI and UA compared to that of STEMI (9\% and 8.8\% vs. $52 \%$ ). The present data were collected from 3 hospitals. Two of these hospitals are recognized as advanced emergency medical service centers; therefore, paramedic emergency medical technicians might transport patients with STEMI to these hospitals when their ECG clearly show elevation of the STsegment, accounting for the increased numbers of patients with STEMI. As seen in Table 4, however, hsTnT was the most sensitive biomarker, and H-FABP the most specific one, in patients with NSTEMI or STEMI; thus, the ratio of STEMI to NSTEMI patients is not likely to have influenced the results. Moreover, the present NSTEMI patient data correspond to those of a previous report. ${ }^{24}$

In conclusion, the hsTnT assay is an excellent diagnostic test that can be performed to rule out ACS in patients with chest pain but, due to its high sensitivity, it is prone to falsepositive testing. Overall, the diagnostic performance of the hsTnT biomarker is similar to that of H-FABP. Moreover, in cases in which patients present at the emergency department soon after the onset of chest pain, the combined use of MPO and H-FABP is optimal for improving the early diagnosis of ACS.

\section{Acknowledgments}

We would like to thank Noriko Hirose and Maki Kudo for providing technical support. This study was supported by a Grant-in-Aid for Scientific Research (no. 20590840) and a Grant for Clinical Vascular Function (K.I.).

\section{Disclosures}

None. 


\section{References}

1. Chan CP, Wan TS, Watkins KL, Pelsers MM, Van der Voort D, Tang FP, et al. Rapid analysis of fatty acid-binding proteins with immunosensors and immunotests for early monitoring of tissue injury. Biosens Bioelectron 2005; 20: 2566-2580.

2. Alhadi HA, Fox KA. Do we need additional markers of myocyte necrosis: The potential value of heart fatty-acid-binding protein. $Q J M$ 2004; 97: 187-198

3. Hsu BG, Chen YC, Lee RP, Lee CC, Lee CJ, Wang JH. Fasting serum level of fatty-acid-binding protein 4 positively correlates with metabolic syndrome in patients with coronary artery disease. Circ $J$ 2010; 74: 327-331.

4. Zhang R, Brennan ML, Fu X, Aviles RJ, Pearce GL, Penn MS, et al. Association between myeloperoxidase levels and risk of coronary artery disease. JAMA 2001; 286: 2136-2142.

5. Meuwese MC, Stroes ES, Hazen SL, van Miert JN, Kuivenhoven JA, Schaub RG, et al. Serum myeloperoxidase levels are associated with the future risk of coronary artery disease in apparently healthy individuals: The EPIC-Norfolk Prospective Population Study. J Am Coll Cardiol 2007; 50: 159-165.

6. Chang LT, Chua S, Sheu JJ, Wu CJ, Yeh KH, Yang CH, et al. Level and prognostic value of serum myeloperoxidase in patients with acute myocardial infarction undergoing primary percutaneous coronary intervention. Circ J 2009; 73: 726-731.

7. Ridker PM, Cook N. Clinical usefulness of very high and very low levels of C-reactive protein across the full range of Framingham Risk Scores. Circulation 2004; 109: 1955-1959.

8. Miller M, Zhan M, Havas S. High attributable risk of elevated C-reactive protein level to conventional coronary heart disease risk factors: The Third National Health and Nutrition Examination Survey. Arch Intern Med 2005; 165: 2063-2068.

9. Mantovani A, Garlanda C, Bottazzi B, Peri G, Doni A, Martinez de la Torre Y, et al. The long pentraxin PTX3 in vascular pathology. Vascul Pharmacol 2006; 45: 326-330.

10. Kotooka N, Inoue T, Fujimatsu D, Morooka T, Hashimoto S, Hikichi $\mathrm{Y}$, et al. Pentraxin3 is a novel marker for stent-induced inflammation and neointimal thickening. Atherosclerosis 2008; 197: 368-374.

11. Suzuki S, Takeishi Y, Niizeki T, Koyama Y, Kitahara T, Sasaki T, et al. Pentraxin 3, a new marker for vascular inflammation, predicts adverse clinical outcomes in patients with heart failure. Am Heart $J$ 2008; 155: 75-81.

12. Morrow DA, Cannon CP, Jesse RL, Newby LK, Ravkilde J, Storrow $\mathrm{AB}$, et al; National Academy of Clinical Biochemistry. National Academy of Clinical Biochemistry Laboratory Medicine Practice Guidelines: Clinical characteristics and utilization of biochemical markers in acute coronary syndromes. Circulation 2007; 115: e356e375.

13. Mingels A, Jacobs L, Michielsen E, Swaanenburg J, Wodzig W, van Dieijen-Visser M. Reference population and marathon runner sera assessed by highly sensitive cardiac troponin $\mathrm{T}$ and commercial car- diac troponin T and I assays. Clin Chem 2009; 55: 101-108.

14. Melanson SE, Morrow DA, Jarolim P. Earlier detection of myocardial injury in a preliminary evaluation using a new troponin I assay with improved sensitivity. Am J Clin Pathol 2007; 128: 282-286.

15. Bakshi TK, Choo MK, Edwards CC, Scott AG, Hart HH, Armstrong GP. Causes of elevated troponin I with a normal coronary angiogram. Intern Med J 2002; 32: 520-525.

16. Fernandes CJ Jr, Akamine N, Knobel E. Cardiac troponin: A new serum marker of myocardial injury in sepsis. Intensive Care Med 1999; 25: $1165-1168$

17. Smith SC, Ladenson JH, Mason JW, Jaffe AS. Elevations of cardiac troponin I associated with myocarditis: Experimental and clinical correlates. Circulation 1997; 95: $163-168$.

18. Inoue K, Sugiyama A, Reid PC, Ito Y, Miyauchi K, Mukai S, et al Establishment of a high sensitivity plasma assay for human pentraxin3 as a marker for unstable angina pectoris. Arterioscler Thromb Vasc Biol 2007; 27: 161 - 167.

19. Yamasaki K, Kurimura M, Kasai T, Sagara M, Kodama T, Inoue K. Determination of physiological plasma pentraxin 3 (PTX3) levels in healthy populations. Clin Chem Lab Med 2009; 47: 471-477.

20. Alpert JS, Thygesen K, Antman E, Bassand JP. Myocardial infarction redefined: A consensus document of The Joint European Society of Cardiology/American College of Cardiology Committee for the redefinition of myocardial infarction. J Am Coll Cardiol 2000; 36: 959-969.

21. Morrow DA, Rifai N, Antman EM, Weiner DL, McCabe CH, Cannon $\mathrm{CP}$, et al. C-reactive protein is a potent predictor of mortality independently of and in combination with troponin $\mathrm{T}$ in acute coronary syndromes: A TIMI 11A substudy: Thrombolysis in Myocardial Infarction. J Am Coll Cardiol 1998; 31: 1460-1465.

22. Daugherty A, Dunn JL, Rateri DL, Heinecke JW. Myeloperoxidase, a catalyst for lipoprotein oxidation, is expressed in human atherosclerotic lesions. J Clin Invest 1994; 94: 437-444.

23. Mad P, Domanovits H, Fazelnia C, Stiassny K, Russmüller G, Cseh A, et al. Human heart-type fatty-acid-binding protein as a point-ofcare test in the early diagnosis of acute myocardial infarction. QJM 2007; 100: 203-210.

24. Kurz K, Giannitsis E, Becker M, Hess G, Zdunek D, Katus HA. Comparison of the new high sensitive cardiac troponin T with myoglobin, h-FABP and cTnT for early identification of myocardial necrosis in the acute coronary syndrome. Clin Res Cardiol 2011; 100: $209-215$.

\section{Supplemental Files}

Supplemental File 1

Table S1. Characteristics of Non ACS Group (False Positive)

Please find supplemental file(s);

http://dx.doi.org/10.1253/circj.CJ-11-0598 